\title{
AN EXPERIMENTAL STUDY ON THE EFFECT OF ALKALI TREATMENT ON PROPERTIES OF KENAF FIBER FOR REINFORCED CONCRETE ELEMENTS
}

\author{
Lam Tian Fook ${ }^{1}$, Jamaludin Mohamad Yatim² \\ ${ }^{I}$ PG Student, Faculty of Civil Engineering, Universiti Teknologi Malaysia, Johor, Malaysia \\ ${ }^{2}$ Assiociate Professor, Faculty of Civil Engineering, Universiti Teknologi Malaysia, Johor, Malaysia
}

\begin{abstract}
Kenaf fibers are coming into interest to use in reinforced concrete elements in recent years due to its attractive properties such as non-abrasive, lightweight and renewable. However, the properties of kenaf fiber such as high moisture absorption and weak in interfacial adhesion make the use of kenaf fiber in reinforced concrete elements become less attractive. Alkali treatment is one of the best used chemical treatment for natural fibers. It help to increase the fiber surface roughness by chemically modify and clean the fiber surface. The purpose of this research is to do a fundamental study on the effects of alkali solutions to the kenaf fiber. There are a lot of researchers conducted study on the effects of different concentrations of NaOH on kenaf fiber. However, there is no information about the study of alkali treatment of kenaf fiber with different $\mathrm{pH}$. Therefore, this study seeks to determine the effects of alkali $\mathrm{pH}$ on the properties of kenaf fiber. By theoretically, the $\mathrm{pH}$ of concrete is around 13, so it is important to have a better understanding on the effects of alkaline to the kenaf fiber especially $\mathrm{pH}$ 13. The finding of the research can help to develop an effective use of fiber in cementitious materials. The problem of water absorption of kenaf fiber could appear if fibers are directly introduced in concrete. For these reasons, in this study, different $\mathrm{pH}$ of $\mathrm{NaOH}$ ( $\mathrm{pH} 8$ to 14) were used and the effects on the colour of fiber, weight loss and water absorption of treated kenaf fibers were evaluated.
\end{abstract}

Keywords: Kenaf fiber; Natural fiber; Alkali treatment; Weight loss; Water absorption

\section{INTRODUCTION}

Kenaf (Hibiscus cannabinus L.) is a warm- season annual herbaceous plant in the Malvaceae family. It has a single, straight, unbranched stem. The fibers in kenaf are found in the outer fibrous bast and an inner woody core. The fiber length is generally longer than one meter but it depends primarily on the location of production. In Malaysia, kenaf grows quite quickly and it stalks can growing to about 14 feet in a 4 to 5 month growing season and $1-3 \mathrm{~cm}$ in diameter. According to U.S. Department of Agriculture, the kenaf yield of about 10 tons of dry fiber per acre per year are generally about 5 times greater than the yield for pine trees which can take from 7 to 40 years to reach harvestable size. Upon harvest, the mechanical fiber separator similar to a cotton gin was used for kenaf processing. Kenaf was used as a source of textile fiber to manufacture rope, twine, sackcloth and paper for over six millennia. The high interest to plant kenaf in recent years is due to the finding of some researchers that kenaf can adsorbs the carbon dioxide in the air and nitrogen and phosphorus in the soil at a significantly high rate. Kenaf fibers are the highest level of carbon dioxide absorption among the fiber crops, it absorbs approximately 1.5 times carbon dioxide per weight [1]. Kenaf fibers are coming into interest of many researchers due to its attractive properties such as non-abrasive, degradable, renewable and inexpensive. The low weight and density, inexpensive makes the kenaf fibers an attractive alternative to traditional reinforcement materials such as steel fiber and glass fiber.
The concept of using natural fibers as an alternative to increase the structural properties of cementitious material is not a new process. Since ancient times, fibers have been used in construction to reinforce brittle materials. Egyptians used straw to reinforce mud bricks and horse hair was used in masonry mortar to provide additional strength. In the 1900 s, asbestos was used in the concrete to protect the concrete from cracks formation. But in the late 19th century, the concept of composite materials came into being and fiber reinforced concrete was come to interest and over looked for 5-6 decades. In the last decades, codes regarding the steel fiber reinforced concrete are being developed [2]. Research into new fiber reinforced concretes continues today.

Kenaf fiber could be utilized as reinforcement materials for cementitious composites and as a viable alternative to traditional reinforcement such as steel fiber. However, the disadvantages of kenaf fiber like poor surface roughness and high moisture absorption lead to their poor mechanical properties and poor fiber-matrix adhesion in composites, and limit their application. The theoretical performance of a composite material was control by the mechanical and physical properties of the matrix mixed and also the strength of bond between the two. Hence, chemical treatment are applied to modify their structural and fiber morphology to improve its mechanical properties. There are various chemical treatments that can be used such as alkali treatment, silane treatment, acetylation treatment and peroxide treatment $[3,4]$. 
In this study, alkali treatment was chosen because it is an effective and popular method to chemically clean and modify the fiber surface. It also increase the possibility of interfacial interaction between fiber and cement matrix. Some studies have been discussed and proved that alkali treatment has significantly improved the surface of the fiber due to the removal of lignin, wax and oils from the external surface of fiber. Sgriccia et al. [5] confirmed that the alkali treatment can removed the hemicellulose from the fiber. Several researchers used alkali treatment on kenaf fiber to improve its surface morphology and fiber mechanical properties. Edeerozey et. al., (2007) [3] used 3\%, 6\% and $9 \% \mathrm{NaOH}$ treatment on kenaf fiber and the optimum concentration of $\mathrm{NaOH}$ was 6\%. Cao Y. et. al., (2007) [6] used $5 \%, 10 \%$ and $15 \% \mathrm{NaOH}$ solutions to treat kenaf fibers and noted the tensile strength of fiber increase for $5 \% \mathrm{NaOH}$ treatment and decrease for $10 \%$ and $15 \% \mathrm{NaOH}$ treatment.

\section{MATERIALS AND METHODS}

\subsection{Kenaf Fiber}

Kenaf fiber used were obtained from National Tobacco Board at Kelantan, Malaysia. The raw fibers were extracted from its stalks by water retting process. The fibers after the water retting process had to wash with water to remove the impurities and then dried under the sunlight before they delivered to us. The bulk fiber density of the fiber used was $1.2 \mathrm{~g} / \mathrm{cm} 3$.
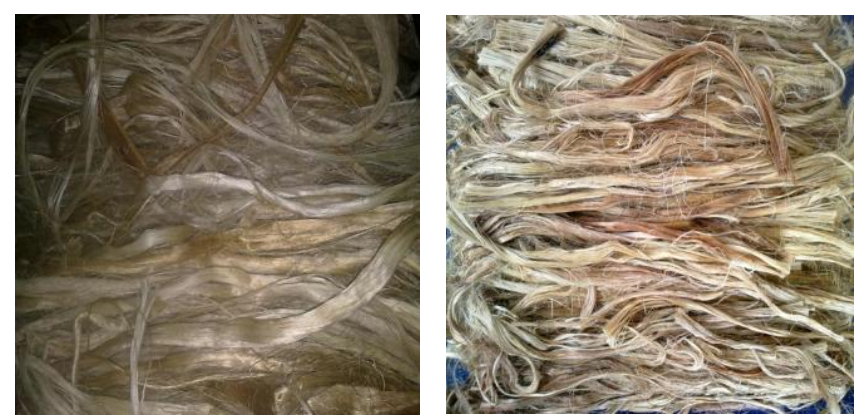

Fig -1: Untreated Kenaf fibers Fig -2: Treated Kenaf Fibers

\subsection{Kenaf Fiber Chemical Treatment}

Raw kenaf fibers were chopping into length of $\pm 15 \mathrm{~cm}$ and weight to \pm 10 gram by using weighing scale before the chemical treatment. A number of 10 samples of fibers were prepared for each $\mathrm{pH}$ solutions. Kenaf fibers were then soaked in $\mathrm{NaOH}$ solutions of different $\mathrm{pH}(\mathrm{pH} 8,9,10,11$, 12,13 and 14) for 3 hours at ambient temperature followed by washing with distilled water to remove traces of alkali. The washing process was repeated and continued until the water after washing approximately $\mathrm{pH} 7$. After that, fibers were dried at ambient temperature for 72 hours.

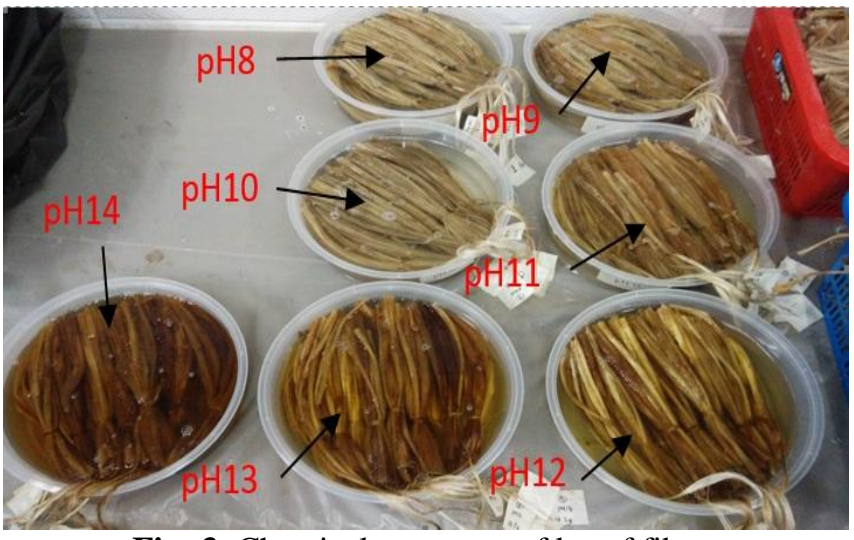

Fig -3: Chemical treatment of kenaf fibers

\subsection{Weight Loss Study}

The weight loss of treated kenaf fibers were investigated. A total number of ten bundles of fibers $( \pm 10 \mathrm{~g})$ were weight by using the weighing scale before it was undergone the chemical treatment. After the chemical treatment, treated fibers were weight and the different intervals between before and after treatments were the weight loss. Weight loss of fibers was computed as follows,

$$
\text { Weight Loss }(\%)=[(\mathrm{Wo}-\mathrm{Wt}) / \mathrm{Wo}] \times 100
$$

Where, Wo and Wt denote the weight of fibers before chemical treatment and the weight after chemical treatment.

\subsection{Water Absorption Study}

Water absorption studies on treated and untreated kenaf fibers were carried out in accordance with ASTM D570-10 [7]. In order to measure the moisture content of kenaf fiber, the fiber was immersed in distilled water at ambient temperature. The water immersed fibers were taken out at regular time interval and the excess water on the fiber surface was dried using paper towl before weighing. After weight measurement the sample were immersed again in water. The process was repeated and continued until saturation period was reached and it stopped after 60 minute. Ten bundles of fibers $( \pm 10 \mathrm{~g})$ were tested, and the average of ten were represent the results. Untreated kenaf fibers were used as a control. The weight of the fibers was measure at regular time intervals and the moisture content was calculated as

$$
\text { Moisture Content }(\%)=[(\mathrm{w} 2-\mathrm{w} 1) / \mathrm{w} 1] \times 100
$$

Where, w1and w2 denote the initial weight of dried kenaf fiber and weight after time $t$, respectively.

\section{RESULTS AND DISCUSSION}

\subsection{Colour of Kenaf Fiber}

The effect of alkali treatment on kenaf fiber can be seen by colour change after the treatment. When the $\mathrm{pH}$ increased, the colour of kenaf fiber become more and more yellowish. This may due to the removal of waxy layer and impurities from the fiber surface. The surface of treated kenaf fiber 
becomes rather smoother as compared to that of untreated kenaf fiber. Based on the colour changes, it was found that higher $\mathrm{pH}$ are more effective to modify the fiber structure to obtain better mechanical properties. The observation suggest that $\mathrm{NaOH}$ was efficient in removing lignin, wax, and oils that cover the external surfaces of the cell wall. After alkali treatment, the fiber surface was clean and smoother. As a consequence: (i) the possibility of interfacial interaction between the cement matrix and the reinforcing fibers, (ii) effective surface area are increase and make the possibility of contact between the fiber and cement matrix, and (iii) the load transfer between the fiber and cement matrix are possible.

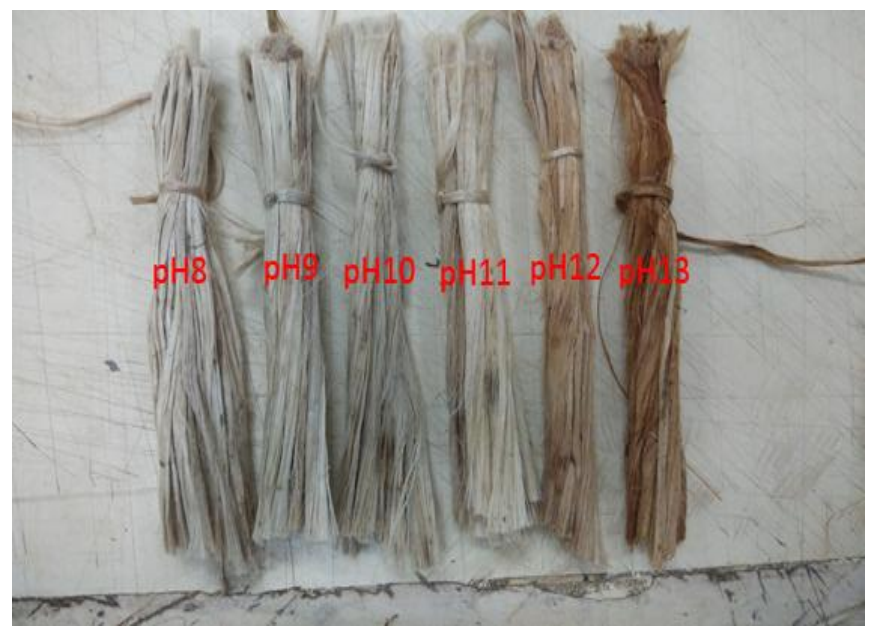

Fig -4: Colour of kenaf fibers after treatment

\subsection{Weight Loss}

The weight of kenaf fiber was measured both before and after the alkali treatment in order to evaluate fibers weight loss. The results are shown in Table 1.

Table -1: Weight loss of kenaf fibers after alkali treatment

\begin{tabular}{|l|l|l|l|}
\hline pH & $\begin{array}{l}\text { Number of } \\
\text { specimens }\end{array}$ & $\begin{array}{l}\text { Weight } \\
\text { loss }(\%)\end{array}$ & St. dev. \\
\hline 8 & 10 & 0.2 & 0.040 \\
\hline 9 & 10 & 0.2 & 0.046 \\
\hline 10 & 10 & 0.4 & 0.049 \\
\hline 11 & 10 & 0.5 & 0.050 \\
\hline 12 & 10 & 0.8 & 0.040 \\
\hline 13 & 10 & 2.5 & 0.128 \\
\hline 14 & 10 & 8.1 & 0.114 \\
\hline
\end{tabular}

From the results obtained, it was found that the mass loss of samples for $\mathrm{pH} 8$ to $\mathrm{pH} 12$ was small. However, $\mathrm{pH} 13$ and 14 showed higher mass loss compared to the others. The higher $\mathrm{pH}$ treated kenaf fibers had the highest weight loss values. This was explained by the increase of $\mathrm{pH}$ that contributes to the increase the strength to clean and modify the fiber surface. The main factors causing the weight loss of fibers was due to the removal of lignin, hemicellulose, pectin and impurities during the alkali treatment process.

\subsection{Water Absorption}

The results obtained from the study reveals that the moisture absorption capability of kenaf fiber was increased by alkali treatment. In addition, the moisture absorption of the treated kenaf fiber increase with an increase in alkaline $\mathrm{pH}$. From the Chart 1, it shows that the moisture content increased with time. The weight of fiber increased sharply at the beginning of the curve, it demonstrating the rapid water molecules penetrate into the fiber and inducing the weight gain. It can be seen that the treated kenaf fibers absorb water very rapidly at the initial stage compare to untreated kenaf fibers. It can attained saturation level very quickly. This is because chemical treatment improved the surface of the fiber by remove a certain amount of lignin, wax, and oils that cover the external surfaces of the cell wall. Because of this, the kenaf fibers have high tendency to absorb moisture. Water absorption of kenaf fiber increases after chemical modification. Water absorption of untreated kenaf fiber is $340 \%$ but increases to $345-395 \%$ after alkali treatment. The time for the untreated kenaf fiber to fully saturated in water was 40 minutes but reduces to $10-15$ minutes after alkali treatment. The highest the $\mathrm{pH}$, the shortest the time for kenaf fiber to reach saturation level.

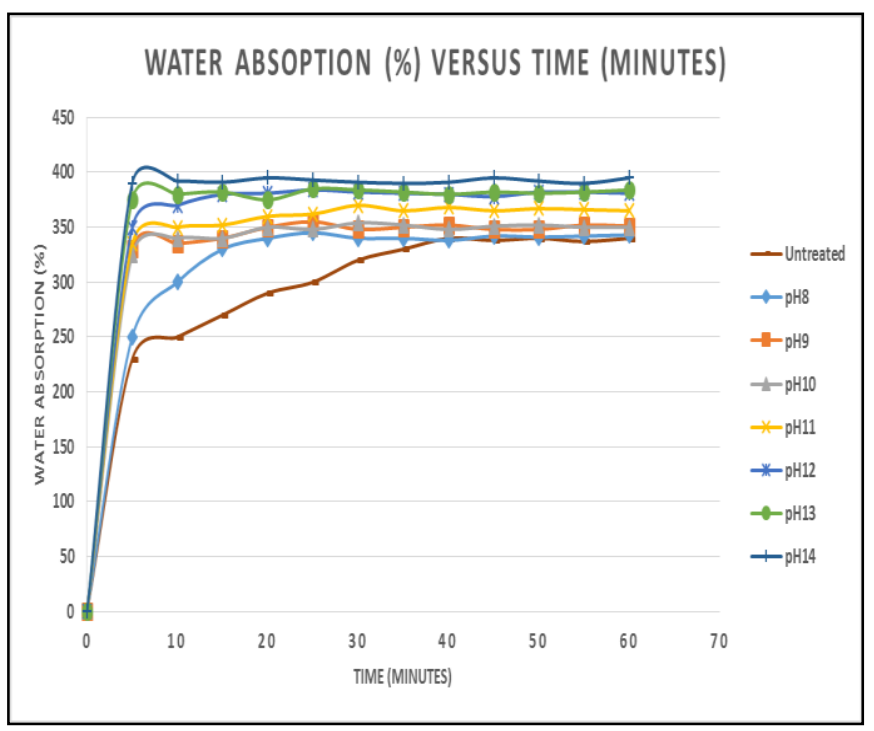

Chart -1: Water absorption vs time

\section{CONCLUSION}

The main conclusions that can be drawn from this study are as follow:

1. Kenaf fiber colour significantly changed due to the alkali treatment. The colour of the fiber becomes more and more yellowish whenever the $\mathrm{pH}$ of $\mathrm{NaOH}$ increased.

2. Treated kenaf fibers were lighter than untreated fibers due to the weight loss after treatment.

3. Treated kenaf fibers have higher water absorption than untreated kenaf fibers. The time for treated kenaf fibers to reach saturation level also reduced. 


\section{REFERENCES}

[1] Mohanty AK., Misra M., Drzal LT. Natural fibers, biopolymers, and biocomposites, CRC Press, Taylor and Francis Group;2005.

[2] ASTM A820-11. Standard Specification for Steel Fibers for Fiber Reinforced Concrete. 2011.

[3] Edeerozey A. M., Hazizan M. A., Azhar A. B. and Zainal Ariffin M. I. Chemical Modification of Kenaf Fibers. ScienceDirect, Material Letters 2007;61:2023-2025.

[4] Rakesh K., Sangeeta O. and Aparna S. Chemical modifications of natural fiber for composite material. Der Chemica Sinica., 2011, 2(4) :219-228.

[5] Sgriccia N., Hawley MC. and Misra M. Characterization of natural fiber surfaces and natural fiber composites. Composites: Part A 2008;39:16321637.

[6] Cao Y., Sakamoto S. and Goda K. Effects of heat and alkali treatments on mechanical properties of kenaf fibers. 16th International Conference on Composite Materials, 2007.

[7] ASTM D570. Standard Test Method for Water Absorption of Plastics. American Society for Testing of Materials. 2010. 